
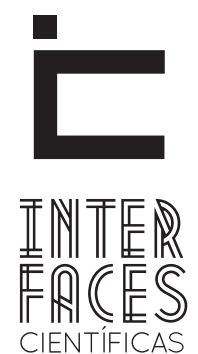

EDUCAÇÃO

ISSN IMPRESSO 2316-333X

E-ISSN 2316-3828

DOI 10.17564/2316-3828.2016v4n2p33-42

\title{
A VARIAÇÃO LINGUÍSTICA E O TEXTO DISSERTATIVO-ARGUMENTATIVO: DISCURSOS [IN]FORMAIS
}

Auda Valéria do Nascimento Ferreira ${ }^{1}$

\section{RESUMO}

Este artigo apresenta uma análise de conteúdo das idiossincrasias de dois alunos do ensino médio (re) significadas a partir da leitura de textos dissertativo-argumentativos acerca da temática da variação linguística, que corroboram com as prescrições dos Parâmetros Curriculares Nacionais do Ensino Médio (PCNEM). 0 objeto é a abordagem das variedades linguísticas segundo os pressupostos sociolinguísticos, e o objetivo, contribuir com as pesquisas experimentais em sala de aula que versam acerca desses pres- supostos. Fundamentamos este estudo com base em Bortoni-Ricardo (2004), Faraco (2008) e Coroa (2008). As análises apontam avanço significativo na compreensão das variedades linguísticas por parte dos alunos.

\section{PALAVRAS-CHAVE}

Variação Linguística. Texto Dissertativo-argumentativo. Prática Pedagógica. 


\section{ABSTRACT}

This article presents a content analysis of idiosyncrasies of two high school students (re)signified from reading dissertative-argumentative texts on the theme of linguistic variation, which corroborate with the requirements of the Parâmetros Curriculares Nacionais do Ensino Médio (PCNEM). The object is to explore the linguistic varieties, according to the assumptions sociolinguistic, and in order to contribute to the experimental research in the class room that talk about these assumptions. This study is based on Bortoni-Ricardo
(2004);Faraco(2008) and Coroa(2008).The analyzes suggest a significant advance in the understanding of linguistic varieties from the students.

\section{KEYWORDS}

Linguistic variation. Dissertative-argumentative text. Teaching practice.

\section{RESUMEN}

En este artículo se presenta un análisis de contenido de las idiosincrasias de dos alumnos de la educación secundaria (re)significadas desde la lectura de textos expositivo-argumentativos acerca del tema de la variación lingüística, lo que corrobora con los requisitos del plan de estudios de Parâmetros Curriculares Nacionais do Ensino Médio (PCNEM). El objetivo es explorar las variedades lingüísticas de acuerdo con los supuestos sociolingüísticos, y su objetivo es contribuir a la investigación experimental en el aula que hablan de estos presupuestos. Basamos este estudio en Bortoni-Ricardo (2004); Faraco (2008) y la Coroa (2008). Los análisis muestran un avance significativo en la comprensión de las variedades del lenguaje de los estudiantes.

\section{PALABRAS CLAVE}

Variación lingüística. Texto expositivo-argumentativo. Práctica pedagógica. 


\section{INTRODUÇ̄̃̃O}

Não apenas na sala de aula, mas principalmente nela, há, frequentemente, distorções nas abordagens acerca da variação linguística. A fim de dirimir dúvidas, fomentar reflexões e, outrossim, direcionar práticas pedagógicas adequadas ao contexto histórico da evolução da língua portuguesa, os Parâmetros Curriculares Nacionais (PCN) e os Parâmetros Curriculares Nacionais do Ensino Médio (PCNEM) evidenciam a contribuição da sociolinguística para fundamentar uma abordagem pedagógica dos fenômenos linguísticos em sala de aula.

No entanto, vimos muitas abordagens de leitura de textos com linguagem informal, a exemplo de letras de música, como Saudosa Maloca, de Adoniram Barbosa, pela especificidade do gênero que o reporta, serem descaracterizadas, terem suas linguagens transportadas para outra forma de dizer: a norma culta/comum/standard, como diz Faraco (2008), privilegiada a ponto de macular a originalidade expressiva de um modo de dizer genuíno, transmitido em um gênero que por si só dispensa outras configurações. É necessário mudar a concepção de língua de alguns professores para que estes suscitem em seus alunos à compreensão da heterogeneidade linguística.

Ao escolhermos qual gênero textual usar, selecionamos um modo de dizer, seja uma conversa informal, seja uma conferência; por meio de um relatório científico ou um relato pessoal. Enfim: os gêneros são orais e/ou escritos, formais ou informais. A variação linguística está para os gêneros textuais como estes estão para as interações sociais: com adaptações a serem consideradas ao longo da escolaridade do aluno. Não há "certo e errado", como insiste a mídia televisiva; há adequações de linguagens conforme as circunstâncias de comunicação. Para desenvolver-se linguisticamente, o aluno precisa conhecer sua linguagem e a do outro, respeitar os contextos de uso nos quais está ou estará predisposto a interagir.
Assim sendo, Saudosa Maloca traz um retrato do paulistano que circula em seu bairro e fala num dos modos tipicamente brasileiros. 0 exagero coloquial da letra é um recurso estilístico do autor. Se o eu-lírico outra linguagem falasse, não haveria poesia na música. Na sala de aula, o professor deve apresentar o texto em propostas coerentes com sua concepção de língua, que precisa ser construída à luz dos pressupostos sociolinguísticos; ao contrário, corremos o risco de retrocedermos ao tempo em que não havia documentos oficiais que direcionassem a abordagem da variação linguística.

Para exemplificar essa discussão, este artigo traz uma experiência com alunos de ensino médio à luz dos pressupostos da variação linguística. Para tanto, selecionamos, como estratégia de trabalho em sala de aula, textos predominantemente dissertativo-argumentativos, a fim de apresentar aos alunos pontos de vistas diferentes acerca da temática da variação linguística e observar as suas idiossincrasias, posteriormente, sobre o mesmo tema.

Diante dos objetivos teórico-empíricos propostos para este trabalho, alavancamos os estudos de Bakhtin (1979), Bortoni-Ricardo (2004), Coroa (2008), Dionísio e Bezerra (2005), Faraco (2008), Koch (2006), Marcushi (2001; 2008), Rudio (1986) e Stubbs (2002).

\section{VARIAÇÃO LINGUÍSTICA E MONITORAMENTO ESTILÍSTICO}

Atualmente, circulam, na sala de aula, textos de diversos tipos e gêneros: comunicações pessoais e públicas; textos instrucionais e acadêmicos. Cada um deles traz suas variações num continuum da fala para a escrita, de estilos menos aos mais monitorados. E, mesmo que haja um maior monitoramento na escrita, está evidente que a escrita é tão heterogênea quanto 
a fala e, obviamente, diante da diversidade de gêneros textuais está a diversidade linguística.

A propósito, comenta Marcuschi (2001, p. 68):

[...] desfaz-se o mito de que a fala é o lócus da informalidade e a escrita, o da realização formal da língua. 0 certo é que formal/informal, tenso/distenso, controlado/livre, elaborado/solto etc. são usos e não atributos da língua. Muito menos características de uma modalidade de uso da língua. (MARCUSCHI, 2001, p. 68).

Segundo Bortoni-Ricardo (2004), os fatores influenciadores do monitoramento estilístico são: 0 ambiente, o interlocutor e o tópico da conversa. De um modo geral, a autora assim se refere ao ato de monitoramento dos estilos de linguagem:

[...] Quando vamos mudar de estilo, passamos metamensagens ou pistas, que podem ser verbais ou não verbais e que transmitem informações do tipo: 'isso é uma brincadeira', 'estou falando sério', 'estou ralhando com você'. A variação ao longo do contínuo de monitoração estilística tem, portanto, uma função muito importante de situar a interação dentro de uma moldura ou enquadre. As molduras servem para orientar os interagentes sobre a natureza da interação: se é uma 'brincadeira', uma 'declaração de amor', uma 'queixa', uma 'admoestação', um 'xingamento’, uma ‘explicação', uma 'crítica', um 'pedido de ajuda'. (BORTONI-RICARDO, 2004, p. 63).

O fato de que cabe à escola aceitar a variante do aluno é comentado por Stubbs (2002, p. 111):

0 aluno deve se adaptar à escola, mas a escola também deve se adaptar ao aluno. Uma posição equilibrada postula que o aluno tem de aceitar a realidade social da língua da escola, e a escola tem de respeitar $\mathrm{a}(\mathrm{s})$ língua(s) do aluno.

O autor propõe uma posição pedagógica coerente ao escrever que os professores têm a responsabilidade de ensinar aos alunos o padrão linguístico dominante, contudo, sem depreciar a língua materna deles. Esclarece também o fato de os professores não conseguirem corrigir a língua falada das crianças como, inclusive, não ser adequado fazê-lo. Se em dado estágio elas se virem motivadas a aprender formas prestigiadas de fala, o processo será dado sem treinamento explícito.

Diante da realização de uma regra não-padrão em sala de aula, Bortoni-Ricardo (2004) sugere a pedagogia culturalmente sensível a partir de duas estratégias: a identificação da diferença e a conscientização da diferença. Segundo a autora, para realizar a primeira, o professor precisa estar atento e conhecer as regras, enquanto que, para a segunda, suscita outras dificuldades. É necessário conscientizar o aluno em relação às diferenças para que ele procure monitorar seu próprio estilo, mas não de modo preciso, no momento em que o aluno está em seu turno de fala. A conscientização deve ocorrer de modo a não interromper o raciocínio do aluno.

Assim, podemos inferir que as noções de certo e errado no uso da língua são pertinentes quando relacionadas à escolha do gênero textual. 0 nível de formalidade ou informalidade dependerá do gênero textual. Alguns só admitirão construções de sentido sob o uso da norma de prestígio. Há aqueles que admitem abreviaturas, gírias, usos mais informais para aproximar os interlocutores ou como estratégia de eficácia de comunicação (COROA, 2008).

\section{TIPO DISSERTATIVO-ARGUMENTATIVO}

Julga-se ser necessário salientar a intenção de destacar o tipo textual ao contrário de alavancar uma justificativa da escolha dos gêneros textuais apresentados neste artigo.

Como se vê em Bakhtin (1979), não há comunicação verbal senão por meio de gêneros textuais, que são inúmeros, mas não infinitos, evidentemente. De qualquer modo, os tipos textuais são sequências linguísticas (sequências retóricas) limitadas, sem probabilidade de aumentar e abrangem as seguintes categorias, de acordo com Marcushi (2008, p. 155): 
O conjunto de categorias para designar tipos textuais é limitado e sem tendência a aumentar. Quando predomina um modo num dado texto completo, dizemos que esse é um texto argumentativo ou narrativo ou expositivo ou descritivo ou injuntivo.

Hoje, ao caracterizarmos um texto como dissertativo, conduzimos os leitores ao entendimento de que determinado gênero textual possui sequências linguísticas predominantemente dissertativas, ou seja, que a maioria dessas sequências expõe uma ou mais teoria(s) acerca de um fenômeno socioeconômico, político e/ou cultural. Se tais sequências ocupam-se apenas disso, temos predomínio do tipo dissertativo-expositivo.

No caso de o autor do texto enveredar pela intencionalidade argumentativa, ou seja, apresentar justificativas, razões, explicações, a fim de persuadir o leitor sobre seu ponto de vista, certamente, irá tecer um texto predominantemente dissertativo-argumentativo.

Há autores, como Koch (2006), que defendem a sinonímia dos termos dissertação/argumentação, a fim de questionar que naturalmente dissertamos ao argumentarmos.

Contudo, encaminhamos, para este trabalho, sinônimos observados no suporte empírico em que circulam os textos escolares, quais sejam os livros didáticos do Programa Nacional do Livro Didático (PNLD). Em grande parte desses livros, o termo dissertativo-expositivo está para a ideia de dissertação, assim como dissertativo-argumentativo, para argumentação. Esta última designação também compõe as orientações para elaboração da redação do ENEM. Desse modo, justificamos a nossa escolha terminológica.

O porquê de priorizarmos a tipologia textual em relação aos gêneros textuais ocorreu diante do nosso objetivo em sala de aula: pretendíamos conduzir os alunos à leitura de textos que alavancassem pontos contraditórios acerca da temática da variação linguística e, posteriormente, provocá-los a dissertar e argumentar segundo seus próprios pontos de vista.

\section{PERCURSO METODOLÓGICO}

Com base nos objetivos propostos, esta pesquisa é do tipo experimental porque verifica a relação de causalidade que se estabelece entre variáveis designadas como independentes e dependentes. "Na pesquisa experimental, o pesquisador manipula deliberadamente algum aspecto da realidade, dentro de condições anteriormente definidas, a fim de observar se produz efeitos" (RUDIO, 1986, p. 69).

Realizamos a pesquisa em sala de aula com 29 alunos do $2^{\circ}$ ano do ensino médio de uma escola pública da região metropolitana brasileira.

Na etapa da análise, deliberamos o trabalho a partir de uma amostra devido à quantidade de dados. Assim, foram escolhidos, aleatoriamente, de cada uma das turmas envolvidas no estudo oito alunos compondo uma amostra de dezesseis no total. Contudo, para composição do presente artigo, analisamos os resultados de dois alunos: Marcos e Joana ${ }^{1}$, jovens de 18 anos.

No início da pesquisa, foi aplicado o pré-teste em que se solicitou que os alunos escrevessem um texto dissertativo-argumentativo sobre o tema variedades linguísticas. Cada aluno elaborou o seu texto - reservado para análise apenas ao final da experiência.

\section{AS IDIOSSINCRASIAS SOBRE LÍNGUA REVELADAS NO PRÉ-TESTE E PÓS-TESTE}

No primeiro contato com a turma, antes de iniciarmos as atividades de leitura, realizamos o pré-teste com os alunos. Solicitamos a elaboração de um pequeno texto nos modos, a saber: "Escreva um texto dissertativo sobre o uso da linguagem popular e da linguagem culta no seu cotidiano. Dê um título para o seu texto".

1. Nomes fictícios. 
Na sequência, a partir da leitura de textos dissertativo-argumentativos (TAKAZAKI, 2005) selecionados especificamente por apresentarem contradições em seus pressupostos temáticos, propusemos aos alunos que escrevessem entre 20 e 30 linhas acerca da discussão: norma-padrão versus o modo como a língua é usada no dia a dia pelos falantes do português brasileiro.

\subsection{ANÁLISE DO PRIMEIRO TEXTO DO MARCOS}

0 aluno inicia o texto em primeira pessoa e apresenta os conceitos de linguagem popular e culta com a propriedade que se espera de um aluno neste nível de formação:

Entendo que a linguagem popular é aquela que falamos no dia a dia, que nos acostumamos a falar por estar no meio de uma sociedade que tem aquela forma de linguagem. Já a culta, aquela que seja talvez a forma certa de falar, que nos preocupamos em falar quando estamos em público (Marcos, 18 anos, $2^{\circ}$ ano do ensino médio).

Observa-se claramente que Marcos situa a linguagem no âmbito de sua cultura, que é uma manifestação livre que se dá no processo natural de interação entre pessoas conhecidas, mas também identifica outras variedades. Chamou a atenção o uso do talvez a forma certa de falar’. Esta dúvida se justifica no próximo trecho:

No meu cotidiano, vejo as pessoas falarem de uma forma culta, somente quando estão falando em público, dando palestras, seminários, na TV ou pessoas da classe alta que tiveram bom estudo para ser uma pessoa culta. Já a linguagem popular é mais fácil de ver no dia a dia, quando estamos entre amigos ou família, porque já se acostumaram com aquela linguagem popular (Marcos, 18 anos, $2^{\circ}$ ano do ensino médio).

Aqui se evidencia a concepção de "culto" como algo próprio dos falantes com grau de instrução superior associado à classe social mais favorecida. 0 aluno finaliza o seu texto assim:
Procuro às vezes tentar falar de uma forma culta também quando falo com pessoas que não conheço, ou quando falo em público, mas quando estou entre amigos não me preocupo em falar uma linguagem culta, que é o caso de muitas pessoas (Marcos, 18 anos, $2^{\circ}$ ano do ensino médio)

0 texto apresentou uma concepção de língua heterogênea a depender de fatores sociais e contextos de uso, e o aluno-autor demonstra conhecimento sobre adequação linguística ao revelar que procura falar de modo culto com pessoas que não conhece.

\subsection{ANÁLISE DE FRAGMENTOS DO SEGUNDO TEXTO DO MARCOS}

Neste segundo texto, depois das leituras realizadas em sala de aula e/ou em outros ambientes, o aluno-autor amplia a sua concepção de língua aos usos também da escrita. É possível inferir suas ideias sobre o uso da gramática normativa, como se observa no trecho:

As pessoas hoje em dia se preocupam muito com a questão da língua portuguesa, seja ela falada ou escrita. Querem seguir rigorosamente a norma-padrão da língua, tentando tornar a língua impecável diante da gramática, gerando então preconceitos linguísticos com relação às leis gramaticais. (Marcos, 18 anos, $2^{\circ}$ ano do ensino médio).

Inferimos que, segundo o aluno, gerar "preconceitos linguísticos com relação às leis gramaticais" é confundir variedades linguísticas com norma-padrão. Ao esperar que o uso linguístico seja de acordo com o que determina a gramática, sem qualquer consideração pelo contexto sociocultural do falante, reforça-se o preconceito fundamentado na concepção de que há usos "certos" e "errados" de uma mesma língua. Sobre isso, o aluno questiona, baseando-se no poema motivador de sua produção:

A questão acima "dê-me" e "me dá" ambos os termos não têm nenhuma diferença no sentido da mensagem, embora estejam escritos diferentes gramaticalmente, mas se fôssemos avaliar de acordo com a norma-padrão, "dê-me" estaria correto. Por quê? As duas transmi- 
tem a mesma mensagem e pode-se compreender claramente, mas por causa das normas gramaticais só uma está correta? (Marcos, 18 anos, $2^{\circ}$ ano do ensino médio).

Vimos a noção de "certo" e "errado" muito bem desmistificada no trecho acima. A língua é plural, com variedades, todas inteligíveis. Compreender que há uma forma prestigiada não é mérito apenas das pessoas com um grau maior de escolaridade. Mas questionar a norma-padrão e suas implicações presentes no preconceito linguístico é um avanço no processo de reflexão e adaptação linguística sob uma ótica de não segregação social.

\begin{abstract}
Na minha opinião, são essas normas que impõem diferenças e preconceitos linguísticos, fazendo, assim, com que as classes busquem usar com rigor essas leis gramaticais para tornar a língua mais culta. (Marcos, 18 anos, $2^{\circ}$ ano do ensino médio).
\end{abstract}

Para Marcos, se não existissem normas, não haveria preconceito. Se a gramática impõe um modelo difícil de ser seguido por todos, independente de classe social, compreende-se que é o uso linguístico de acordo com essas normas que torna uma língua culta, e não o uso que as pessoas consideradas cultas fazem da língua. Esta observação representou consistentemente a opinião do senso comum, porém, o aluno prossegue sua reflexão:

Mas, se os dois termos, estão transmitindo claramente uma mensagem só, então não poderia estar uma erra$\mathrm{da}$, com isso se as pessoas parassem para pensar nisto, não haveria nenhum problema de usar 'me dá' tanto na linguagem escrita como na falada, basta apenas ter uma comunicação clara e objetiva, sem regras, para que nas classes prestigiadas e desfavorecidas não exista esse preconceito linguístico e que todos tenham 'liberdade' na escrita e no uso da sua língua (Marcos, 18 anos, $2^{\circ}$ ano do ensino médio).

O fato de o aluno ter utilizado as aspas na palavra “liberdade" suspendeu quaisquer hipóteses da defesa de liberação indiscriminada da língua, da lei do "vale tudo" desde que se compreenda. Ao escrever "basta apenas ter uma comunicação clara e objetiva, sem re- gras" pode ter parecido contraditório, mas o que se defende, na realidade, pela ênfase de liberdade linguística dada no texto, é o combate ao preconceito linguístico.

\subsection{ANÁLISE DO PRIMEIRO TEXTO DA ALUNA JOANA}

De acordo com a proposta de produção de texto apresentada, Joana inicia o texto tratando da linguagem em vez da língua. Mas o importante é que se situa como falante consciente de que sua língua varia conforme o seu contexto sociocultural e de seu interlocutor.

\begin{abstract}
No cotidiano, a linguagem varia conforme haja a necessidade. Há muitas formas de expressão e a linguagem popular nem sempre é a mais conveniente, dependendo de com quem se fala, e de que carga de conhecimento essa pessoa possui.

Em um grupo de estudantes, é normal o uso da linguagem popular, o uso das gírias em conversa entre jovens é um sinal de que se está na moda.

O uso da linguagem culta, porém é mais comum entre pessoas maduras e com grau de instrução elevado. (Joana, 18 anos, $2^{\circ}$ ano do ensino médio).
\end{abstract}

Ela conclui seu texto, abordando a variedade de língua prestigiada ao utilizar o termo “linguagem culta” e situá-la, talvez em alusão à experiência advinda das pessoas de mais idade, ao uso contínuo, ou seja, quanto mais se usa por meio do tempo mais se desenvolve a variedade prestigiada.

\subsection{ANÁLISE DE FRAGMENTOS DO SEGUNDO TEXTO DA ALUNA JOANA}

Joana inicia com um questionamento norteador de todo o seu texto. Demonstra forte senso crítico e usa uma terminologia de acordo com os textos lidos.

Os defensores do "bom uso da língua" pregam o que está contido na gramática normativa, ou seja, os falantes da língua portuguesa devem seguir as normas que são consideradas "certas". Mas quem fala "certo" hoje em dia? Será que quem não segue à risca a norma-padrão é ignorante? (Joana, 18 anos, $2^{\circ}$ ano do ensino médio). 
Ao responder ao seu próprio questionamento, a aluna é categórica e ao mesmo tempo conciliatória. Pelo visto, compreendeu muito bem o contexto de discussão que envolve o tema da variação linguística até a atualidade.

Não. O que todos devemos entender é que os velhos conceitos de língua que estão na gramática não cabem mais no contexto do século XXI. Porém, não se pode simplesmente deixar de lado as normas gramaticais e começar a falar e escrever como bem entender (Joana, 18 anos, $2^{\circ}$ ano do ensino médio)

No trecho a seguir, percebe-se uma extrapolação do que poderíamos analisar como apenas uma visão sociolinguística da língua no nível do ensino médio. Ao trazer a proposta de estudiosos da língua, Joana traduz a ideia da busca pelo uso normal da língua; seria uma norma no sentido de normal e não de normativo.

0 que os estudiosos da língua portuguesa estão propondo é que haja uma reforma na gramática normativa, que seja feita uma atualização, e que daí por diante nós possamos aprender o que realmente se fala e se escreve hoje em dia. Principalmente, em momentos formais (Joana, 18 anos, $2^{\circ}$ ano do ensino médio).

Joana pontua a mudança linguística ao fazer um paralelo com a gramática normativa. Sabe-se disso porque no curso propedêutico em que ela se encontra não se discute outro tipo de gramática. E ela compreende que a noção de erro que se tem em relação à língua, na realidade, refere-se à gramática normativa.

A língua portuguesa está mudando e na gramática nada muda, mesmo estando claro que ninguém fala como se falava no Brasil colonial, a gramática continua a mesma. Sendo assim, já não podemos dizer que existe "certo" ou "errado" do ponto de vista científico da língua (Joana, 18 anos, $2^{\circ}$ ano do ensino médio)

A seguir, a aluna mostra-se sensível à questão do preconceito linguístico, ao mesmo tempo em que se incorpora ao seu próprio discurso numa demonstração de "desabafo". Não se coloca como falante de nenhuma das variedades, não se percebe como falante das variedades "ditas erradas" nem se considera co- nhecedora das normas contidas na gramática, apenas espera no futuro desenvolver os usos da língua.

As variedades estigmatizadas, "ditas erradas" os falantes que teimam em usar a linguagem cotidiana, típica de sua região, esperam ansiosos o dia em que seu modo de falar seja respeitado. E nós esperamos que futuramente tenhamos uma gramática em que não precisemos estudar a vida inteira e ainda assim nada saber. (Joana, 18 anos, $2^{\circ}$ ano do ensino médio).

Desse modo, conclui-se que Joana, assim como Marcos utilizam uma terminologia de acordo com os textos lidos; demonstram conhecer diferenças significativas entre gramática normativa e variedades linguísticas e apresentam proposta de combate ao preconceito linguístico ao defenderem uma gramática que considera as variedades estigmatizadas como legítimas.

\section{CONSIDERAÇÕES FINAIS}

A pesquisa experimental permitiu conhecer como a abordagem culturalmente sensível acerca da temática da variação linguística pode suscitar questionamentos em sala de aula, a partir da compreensão leitora (de dois alunos do ensino médio) de textos dissertativo-argumentativos, e desmistificar práticas pedagógicas que apenas reforçam o preconceito linguístico e direcionam os comportamentos sociais à concepção homogênea de língua, que não é real, nem está contribuindo para a melhoria do ensino no Brasil.

É pertinente ressaltar que os textos utilizados em sala de aula, embora tenham sido selecionados a partir de objetivos de ensino e de aprendizagem, possuem contradições de pontos de vista sobre conceitos de erro, ensino de língua portuguesa e mudança linguística. A intenção de que esses textos tivessem esse viés de tratamento deu-se diante dos mecanismos linguísticos de tessitura das sequências textuais categorizadas como dissertativa-argumentativas. Ou seja, sem discussão, sem contradições, sem significações e/ou ressignificações não há compreensão, não há elementos discursivos para defesa de ponto de vista. 


\section{REFERÊNCIAS}

BAKHTIN, Mikhail Mikhailovich. Os gêneros do discurso. In: BAKHTIN, Mikhail Mikhailovich. Estética da criação verbal. São Paulo: Martins Fontes, 1979.

BORTONI-RICARDO, Stella Mares. Educação em língua materna: a sociolinguística na sala de aula. São Paulo: Parábola, 2004.

BRASIL, Ministério da Educação. Secretaria de Educação Fundamental. Parâmetros curriculares nacionais para o ensino fundamental: terceiro e quarto ciclos do ensino fundamental/língua portuguesa. 1998. Disponível em: <http:// portal. mec.gov.br>. Acesso em: 17 mar. 2008.

BRASIL, Ministério da Educação. Secretaria Média e Tecnológica. Parâmetros curriculares nacionais: ensino médio: linguagens, códigos e suas tecnologias. Brasília: Ministério da Educação, Secretaria de Educação Média e Tecnológica, 1999.

COROA, Maria Luiza. Tipos Textuais. In: Programa Gestão da Aprendizagem Escolar - Gestar II. Língua Portuguesa: caderno de teoria e prática 3 - TP3: gêneros e tipos textuais. Brasília: Ministério da Educação, Secretaria de Educação Básica, 2008.
DIONÍSIO, Angela Paiva. Variedades linguísticas, avanços e entraves. In: DIONÍSIO, Angela Paiva; BEZERRA, Maria Auxiliadora (Org.). 0 livro didático de português: múltiplos olhares. Rio de Janeiro: Lucerna, 2005.

FARACO, Carlos Alberto. Norma culta brasileira: desatando alguns nós. São Paulo: Parábola, 2008.

$\mathrm{KOCH}$, Ingedore Grunfeld Villaça. Argumentação e linguagem. São Paulo: Cortez, 2006.

MARCUSCHI, Luiz Antônio. Da fala para a escrita: atividades de retextualização. São Paulo: Cortez, 2001.

MARCUSCHI, Luiz Antônio. Produção textual, análise de gêneros e compreensão. São Paulo: Parábola, 2008.

\section{RUDIO. Franz Victor. Introdução ao projeto de} pesquisa científica. Petrópolis: Vozes, 1986.

STUBBS, Michael. A língua na educação. In: BAGNO, Marcos; STUBBS, Michael. GAGNÉ, Gilles. Língua materna: letramento, variação e ensino. São Paulo: Parábola, 2002.

TAKAZAKI, Heloísa Harue. Língua portuguesa: volume único: ensino médio: livro do professor. São Paulo: IBEP, 2005. 
1. Mestre em Educação pela Universidade Federal de Alagoas. E-mail: audacoord@yahoo.com.br

Avaliado em: 15 de janeiro de 2016

2. Doutora em Letras e Linguística e professora do Programa de PósAceito em: 29 de janeiro de 2016 